liquids should have a linear temperature dependence, but nowhere makes it clear why the quasi-particles are still fermions, or why the procedure for calculating the specific heat is the same as for a perfect gas and what is the meaning of the effective mass. Another objection I have against the book is the sloppy treatment of names and references: Birkoff instead of Birkhoff, Kammerlingh Onnes as well as Kamerlingh Onnes, Nozier or Nozière, instead of Nozières, Schöfield instead of Schofield, Soviet Phys.-JETP instead of Zh.Eksp.Teor.Fiz. D. TER HAAR

\section{Interference and Waves}

Interference of Electromagnetic Waves. By A. H. Cook. (International Series of Monographs on Physics.) Pp. viii +253. (Clarendon: Oxford ; Oxford University: London, June 1971.) $£ 5$.

INTERFEROMETRY is a discipline which, especially during the past two decades, has intruded more and more into science and engineering. Its classical beginnings were in the visible region of the spectrum, but it has spread over the whole electromagnetic gamut from Xrays to radio waves; it has even sidestepped into de Broglie waves.

Dr Cook's book declares its interest in the electromagnetic spectrum. $\mathrm{He}$ sets out, as he says in the preface, ". . . to deal with selected topics in the interference of electromagnetic radiation in a fundamental way while yet introducing them in an elementary manner". His choice of topics is, not unnaturally, coloured to some extent by his own experience. While in the Standards Division of the National Physical Laboratory (ultimately as its superintendent) he was concerned with extremely precise measurements which included the determination of the density of mercury, the measurement of the acceleration due to gravity and the establishment of the length of the standard yard in terms of the orange wavelength of krypton. In all of these interferometry was used as the method of choice for determining lengths with the utmost accuracy. Inevitably many exponents of interferometry could bridle at the fact that their own specialities have been left out. But, in the samples he has selected, Dr Cook has discussed the underlying principles with sufficient thoroughness to give the reader a clear notion of what goes on in virtually any interferometer. This he has done with the aid of mathematics which are merciful compared with those found in some other books on the same subject.

After introducing the concept of coherence, he devotes much of the book to the Michelson, Fizeau and FabryPerot interferometers and some of their applications. These include X-ray and microwave interferometry. Fourier transform spectroscopy is covered in this part of the book, as is the birefringence filter. A very useful chapter on the general theory of spectrometers is given.

The theory of "angular interferometers", covering Michelson's stellar interferometer and its radio counterpart, is presented in a very interesting chapter. It is a pity that, here, Homer has nodded; Dr Cook implies that the spacing of the fringes in the focal plane can be calculated from the separation of the outside mirrors and the focal length. This can only be done in "starspace"; in fact, the fringe spacing as calculated is wholly unrealizable. (I was "hung up" over this matter many years ago.) The difficulty with the early instruments at Mount Wilson was not the fineness of the fringes but their motion due to the "seeing"; Gebbie and Twiss sought to remedy this, to a first order, by an ingenious servo mechanism.

A short chapter on beats between independent sources reminds the reader firmly that times have changed since R. W. Wood wrote. Finally, the topic of intensity interferometers is discussed, another field of which the title seems at first sight to be a contradiction in terms. Unhappily, the curious jinx on the "angular interferometer" appears again; by an obvious slip of the pen "path difference" is used for "base-line". But, if the reader has absorbed Dr Cook's exposition of basic principles, he should, having read this far in the book, be in no danger of being misled.

These few quibbles-together with a few misprints-detract only negligibly from the value of a book written with clarity and authority. It will be a most useful introduction to a subject about which increasing numbers of scientists need to know.

J. DYson

\section{Palaeoecology Introduced}

An Introduction to Quantitative Paleoecology. By R. A. Reyment. Pp. xiit 226. (Elsevier: Amsterdam, London and New York, 1971.) n.p.

IT is a pleasure to read such a clearly written and disarmingly simple little book whose contents quite belie the somewhat arid title. "How to enjoy using fossils and figures" might have been more apt as a description. The book is a short and very personal account of the way in which one palaeoecologist looks at his subject. $\mathrm{He}$ starts by introducing straightforward statistical concepts and then writes about such topics as the orientation of shells, the ways in which the environment can affect the size and shape of animals, the identification of predators, prey and population dynamics, the distribution of organisms in space, and some of the ways in which fossil assemblages can be analysed using statistical methods.

Part of the charm of the book lies in the twenty-eight case histories. In each example the problem is described, a model proposed, a statistical method and calculation provided, and the results discussed. Most of the examples are directly or indirectly the outcome of the author's own research and tend therefore to rely on ostracods and molluscs and be more concerned with younger than with older rocks. The last forty pages of the book give statistical tables, some short Fortran programs, references and an adequate index.

It does not really matter that the animal kingdom and the geological column have been selectively sampled. More than twenty of the more common statistical methods of particular interest to palaeoecology are described-more than sufficient for many of the present practitioners of the art. The author asks the question in the preface, "Am I kidding myself or is this result, or these data, really genuine? I have tried to do the same thing myself in the following pages but it is not always easy." It is pleasant to record that I believe that Professor Reyment has been successful not only with his data but with his approach. The book should appeal to a wide range of advanced students and thoroughly deserves to be successful.

$$
\text { G. Y. CRatg }
$$

\section{Rubber Text}

Rubber Technology and Manufacture. Edited by C. M. Blow. Pp. xxii +527. (Butterworth: London, May 1971.) $£ 9$.

THE first impression of a book which purports to cover the whole of rubber technology in just over 500 pages is inevitably one of superficiality. The wording on the dust cover implies that this book is "a definitive volume covering rubber technology and manufacture". The foreword says that it is intended (among other things) as a "guide" for undergraduates reading for the AIRI and for degrees in polymer science or technology. The latter is certainly a more realistic assessment, and in consequence some readers may feel that $£ 9$ is an excessive price to pay for what is merely an introduction to the subject. A selection of leading references is given for those who wish to follow up the various topics in greater detail, and this feature enhances the value of the book very considerably.

Most of the principal areas of rubber technology are dealt with, but rarely is space available to permit treatment in any depth. According to the foreword, the brief prepared by the editor stated that "the book is intended for graduates in chemistry, physics and engineering wishing to acquire a sound practical 